\title{
Thermal Annealing Effect on the Morphology of Inkjet Printed Polymer:Fullerene Composites Solar Cells
}

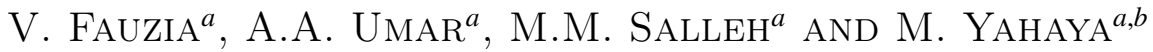 \\ ${ }^{a}$ Institute of Microengineering and Nanoelectronics (IMEN), Universiti Kebangsaan Malaysia \\ 43600 Bangi, Selangor, Malaysia \\ ${ }^{b}$ School of Applied Physics, Faculty of Science and Technology, Universiti Kebangsaan Malaysia \\ 43600 Bangi, Selangor, Malaysia
}

\begin{abstract}
One of critical factor in determining the performance of solar cells is the morphology of the active layer. The drying process of the active layer prepared by inkjet printing technique plays a key role in obtaining high quality surface morphology. This paper reports the effect of thermal annealing on the morphology of printed active layer. The printed active layer is a blend of poly(3-octylthiophene-2,5-diyl) and (6,6)-phenyl $\mathrm{C}_{71}$ butyric acid methyl ester dissolved in a mixture of dichlorobenzene:mesitylene. The printed films were then annealed at three different temperatures, namely 120,140 , and $160^{\circ} \mathrm{C}$ for $60 \mathrm{~min}$ to obtain the best performance of solar cells. It was found that the performance of solar cells strongly depends on the annealing temperature. The devices with the active layer annealed at $140{ }^{\circ} \mathrm{C}$ exhibits the highest performance with short circuit current density and open circuit voltage as high as $2.88 \mu \mathrm{A} / \mathrm{cm}^{2}$ and $0.85 \mathrm{~V}$, respectively. The effect of annealing on the properties of printed active layer will be discussed.
\end{abstract}

PACS: 88.40.jr, 81.05.Fb

\section{Introduction}

Inkjet printing technique is one of many deposition techniques intensively developed to fabricate flexible and large area organic solar cells with low cost production. Inkjet printing technique has been applied mainly for deposition of active layer [1-9] and buffer layer [10] in organic solar cells. For printing the active layer, besides the chemical properties of the active material, the solvent used plays a key role in determining the nature of droplets, film formation and the reliability of the printing process. For example, the use of high boiling point solvent may require a post annealing treatment to transform the material from liquid to solid state and to produce high quality thin films morphology, hence high photovoltaic performance. Recently, there have been an intensive study on the performance of inkjet printed organic solar cells related to the regioregularity of polymer [1], the active material composition [2], the solvent system and drying process [3-9] on the devices.

In this work, we report the effect of annealing temperature on the morphology of active layer consisting of polymer:fullerene composite on the photovoltaic performance. The composite material of blended polymer poly(3-octylthiophene-2,5-diyl) (P3OT) and fullerene derivative $(6,6)$-phenyl $\mathrm{C}_{71}$ butyric acid methyl ester $\left(\mathrm{PC}_{71} \mathrm{BM}\right)$ was dissolved in a mixture of dichlorobenzene:mesitylene (vol. 2:1) and was inkjet printed using Fujifilm Dimatix DMP-2831 Material Printer at the temperature of $140^{\circ} \mathrm{C}$ with a voltage of $14-16 \mathrm{~V}$ and a drop spacing of $26 \mathrm{~nm}$. The printed films were then annealed in vacuum at three different temperatures namely 120,140 , and $160^{\circ} \mathrm{C}$ for $60 \mathrm{~min}$. It was found that the structure and morphol- ogy of printed films strongly depend on the annealing temperature. The optimum annealing temperature that gives high quality (low roughness and compact structure) was $140^{\circ} \mathrm{C}$. The solar cells devices with the active layer annealed at $140^{\circ} \mathrm{C}$ exhibit the highest performance with short circuit current density and open circuit voltage as high as $2.88 \mu \mathrm{A} / \mathrm{cm}^{2}$ and $0.85 \mathrm{~V}$, respectively. The effect of thermal annealing on the performance of the solar cells will be discussed.

\section{Experiments}

The bulk heterojunction organic solar cell fabricated in this work has a structure as shown in Fig. 1. The active layer was sandwiched between a transparent indium tin-oxide (ITO) and an aluminum film. The active layer was composed by $\mathrm{P} 3 \mathrm{OT}$ and $\mathrm{PC}_{71} \mathrm{BM}$ with a weight ratio of 1:1 and then dissolved in dichlorobenzene/mesitylene (vol. 2:1) with a concentration of $1 \mathrm{wt} \%(13 \mathrm{mg} / \mathrm{ml})$. The solution was stirred overnight at ambient temperature in air and it was ready to use as ink after a filtering (using 0.45 PTFE filters) process.

The ink solution was then printed on ITO substrate (7 $\Omega$ /sq) by inkjet printing technique using Fujifilm Dimatix DMP-2831 Material Printer in the glove box with argon atmosphere. Substrates were placed $1 \mathrm{~mm}$ below the inkjet printhead, the temperature of print head was set of $40^{\circ} \mathrm{C}$, the typical printing settings used a voltage in the range $14-16 \mathrm{~V}$ with a pulse width of $20.2 \mu \mathrm{s}$ and the drop spacing of $26 \mu \mathrm{m}$. The wet organic thin films were left to dry slowly in a Petri dish until the color of films changed from orange to purple. The films were 


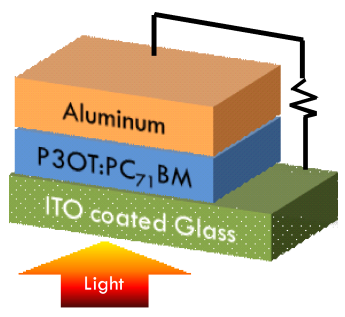

Fig. 1. Structure of P3OT:PC ${ }_{71} \mathrm{BM}$ bulk heterojunction organic solar cells.

then thermally annealed at three different temperatures, i.e. 120,140 , and $160^{\circ} \mathrm{C}$ for $60 \mathrm{~min}$ in vacuum. Finally, the aluminum thin film was deposited through a shadow mask with a thickness of $150 \mathrm{~nm}$ by the electron gun evaporation system.

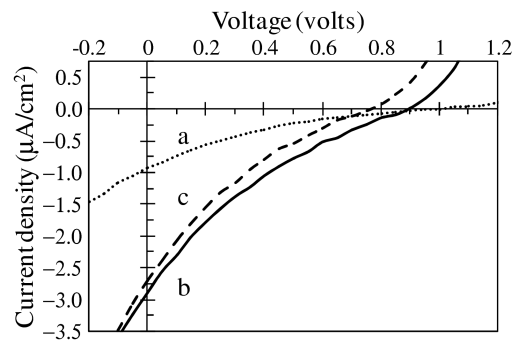

Fig. 2. The current-voltage characteristic of printed P3OT: $\mathrm{PC}_{71} \mathrm{BM}$ composites solar cells that were annealed at (a) $120^{\circ} \mathrm{C}$, (b) $140^{\circ} \mathrm{C}$, and (c) $160^{\circ} \mathrm{C}$.

The surface morphology of composite film was observed by using Ntegra Prima atomic force microscopy (AFM) with semi contact modes. The photovoltaic performance of solar cell devices was observed through current-voltage measurements (Keithley SMU 237) both in the dark and under Newpoint Solar Illumination with AM $1.5\left(100 \mathrm{~mW} / \mathrm{cm}^{2}\right)$ in air. The result is shown in Figure 2.

\section{Results and discussion}

Optical microscopy was used to show a qualitative investigation on the morphology of printed composite films. Figure 3 shows the optical micrograph of P3OT:PC ${ }_{71} \mathrm{BM}$ composite films as printed and after thermal annealing treatment with three different temperatures. Figure 3a reveals the morphology of the as printed film that looked smooth and uniform, whereas Fig. 3b-d shows the annealed films at temperature of 120,140 and $160^{\circ} \mathrm{C}$, respectively. All annealed films looked rough and fulfilled with the black spots. The black spots are thought of as the $\mathrm{PC}_{71} \mathrm{BM}$ crystallites formed during the annealing process. The size and the number of crystallites were increased with the increase of annealing temperature. During annealing treatment, even at $120^{\circ} \mathrm{C}$ (see Fig. $3 \mathrm{~b}$ ), the $\mathrm{PC}_{71} \mathrm{BM}$ molecules were likely to combine, grew in a vertical direction to the film plane and formed a large crystallite of micrometers scale thereby destroying the original morphology of P3OT:PC ${ }_{71} \mathrm{BM}$ composites. Such active $\mathrm{PC}_{71} \mathrm{BM}$ crystallization might occur due to phase separation during the printing process affected by slow evaporation in the printed film. Such process may further enhance as the result of the thermodynamic equilibrium effect [11].
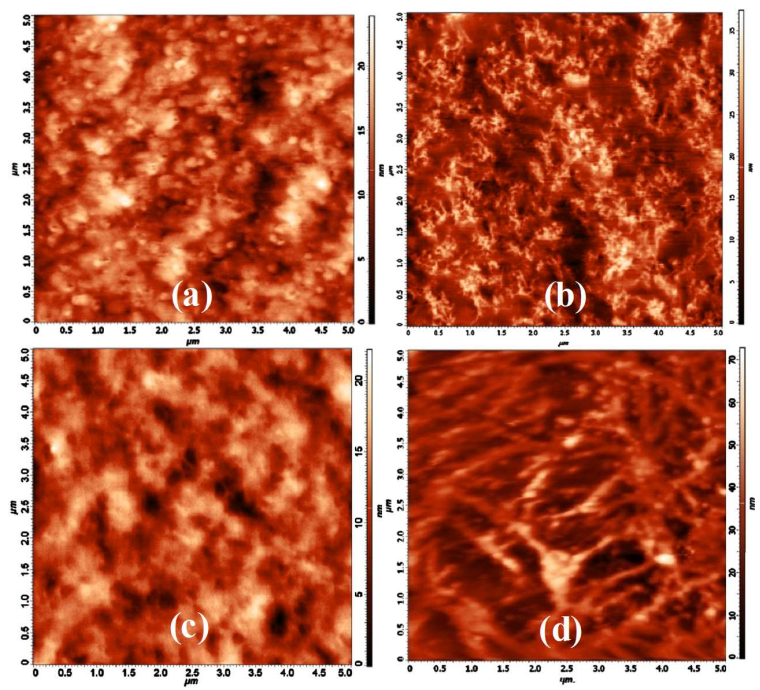

Fig. 3. The AFM images of printed P3OT:PC $\mathrm{P}_{71} \mathrm{BM}$ composite film (a) as printed and after annealing at temperature of (b) $120^{\circ} \mathrm{C}$, (c) $140^{\circ} \mathrm{C},(\mathrm{d}) 160^{\circ} \mathrm{C}$.

The nanoscale morphology of the inkjet printed films is displayed in more detail in AFM images as shown in Fig. 3. On the as printed film as shown in Fig. 3a, the film is relatively smooth and uniform, covering the substrate surface. Unfortunately the annealed film became rougher and contained large scale high crystallites after annealing. The surface roughness was found to increase from $2.49 \mathrm{~nm}$ to $4.21,3.35$, and $5.65 \mathrm{~nm}$ when the films were annealed at 120,140 , and $160^{\circ} \mathrm{C}$ respectively. The increase of surface roughness is correlated to the $\mathrm{PC}_{71} \mathrm{BM}$ crystallization during the annealing process. Moreover, there is unique morphology obtained on the film annealed at $160^{\circ} \mathrm{C}$, in which the long chains of $\mathrm{P} 3 \mathrm{OT}$ polymer were clearly visible, of which the $\mathrm{PC}_{71} \mathrm{BM}$ might concentrate on the certain area of the surface so that the majority of the surface area was covered by P3OT only. Meanwhile, large area microscopy images, as shown in Fig. 1, indicated large morphological difference with each other due to active $\mathrm{PC}_{71} \mathrm{BM}$ crystallization. $\mathrm{AFM}$ images of the films annealed at 120 and $140{ }^{\circ} \mathrm{C}$ also showed clear difference between each other as the result of intense phase separation in the film. As can be seen from the images, the film annealed at $140^{\circ} \mathrm{C}$ showed more compact structure as those in as prepared film, the condition that might facilitate higher photovoltaic response.

The photovoltaic performance of the solar cell devices fabricated using the four samples were studied by 


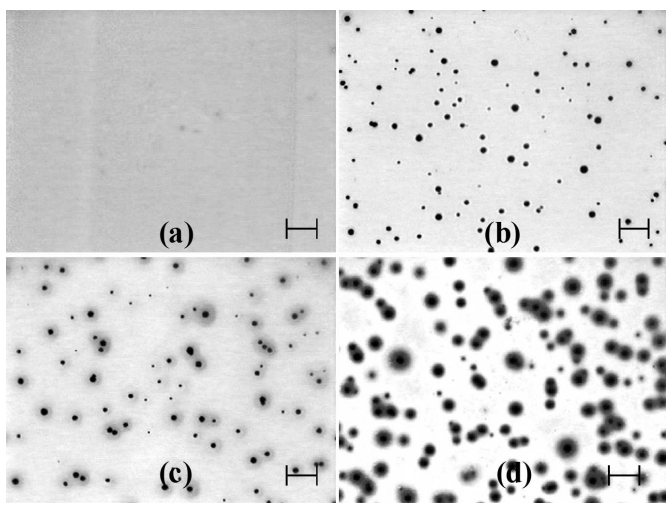

Fig. 4. The optical microscopy images of (a) as printed film and the annealed films at temperature of (b) $120^{\circ} \mathrm{C}$, (c) $140{ }^{\circ} \mathrm{C}$, and (d) $160^{\circ} \mathrm{C}$. The scale bar is $10 \mu \mathrm{m}$.

using current-voltage $(I-V)$ measurement in the dark and under AM 1.5 solar illumination (the intensity of $100 \mathrm{~mW} / \mathrm{cm}^{2}$ ). The result is shown in Fig. 4. It was found that the devices without annealing treatment show no photovoltaic effect, that might be due to the fact that active layer was not fully dried due to the solvent entrapment, so that produced high density of carrier traps in the device. Thus no photovoltaic response was obtained. Meanwhile, for the annealed devices, for examples annealed at $120^{\circ} \mathrm{C}$, the photovoltaic effect was observed with a short circuit density $\left(J_{\mathrm{SC}}\right)$, open circuit voltage $\left(V_{\mathrm{OC}}\right)$ and fill factor $(\mathrm{FF})$ as high as $0.94 \mu \mathrm{A} / \mathrm{cm}^{2}$, $1.00 \mathrm{~V}$, and 0.14 , respectively. The device performance was found to be increased when the annealing temperature increased to $140^{\circ} \mathrm{C}$. At this condition, $J_{\mathrm{SC}}, V_{\mathrm{OC}}$, and $\mathrm{FF}$ improved to $2.88 \mu \mathrm{A} / \mathrm{cm}^{2}, 0.85 \mathrm{~V}$ and 0.17 , respectively. This certainly improved a power conversion efficiency (PCE) up to as high as $4.28 \times 10^{-4} \%$. Unfortunately, the device performance did not further enhanced when the annealing temperature further increased to $160^{\circ} \mathrm{C}$. This might be due to the deterioration in the film as the result of higher annealing temperature. The complete result of photovoltaic performance solar cells devices is summarized in Table.

TABLE

Photovoltaic performance of solar cells devices.

\begin{tabular}{c|c|c|c|c}
\hline \hline $\begin{array}{c}T_{\text {anneal }} \\
{\left[{ }^{\circ} \mathrm{C}\right]}\end{array}$ & $\begin{array}{c}J_{\text {SC }} \\
{\left[\mu \mathrm{A} / \mathrm{cm}^{2}\right]}\end{array}$ & $\begin{array}{c}V_{\mathrm{OC}} \\
{[\mathrm{V}]}\end{array}$ & $\begin{array}{c}\text { Fill } \\
\text { factor }\end{array}$ & $\begin{array}{c}\text { PCE } \\
{[\%]}\end{array}$ \\
\hline 120 & 0.94 & 1.00 & 0.14 & $1.32 \times 10^{-4}$ \\
140 & 2.88 & 0.85 & 0.17 & $4.28 \times 10^{-4}$ \\
160 & 2.69 & 0.75 & 0.17 & $3.49 \times 10^{-4}$
\end{tabular}

\section{Conclusions}

The thermal annealing on the morphology of inkjet printed P3OT:PC ${ }_{71} \mathrm{BM}$ composite film and their photovoltaic performance have been investigated. The annealing treatment of the printed films has induced the phase separation between $\mathrm{P} 3 \mathrm{OT}$ and $\mathrm{PC}_{71} \mathrm{BM}$, which is further significantly modifying the morphology of the film as judged from Figs. 1 and 3. The solar cells devices examination of the samples revealed that the samples annealed at $140^{\circ} \mathrm{C}$ generated higher performance compared to other samples. On the basis of the optical microscopy and AFM images, it can be concluded that the highest performances of the sample annealed at $140^{\circ} \mathrm{C}$ could be due to its relatively compact structure and smoother morphology that facilitate optimum charge transfer in the device. Such compact structure also produced an optimum phase separation inside the film, thus inducing the generation of excitons in the devices. Despite this the as printed film also induced excellent compactness and smooth morphology, however, it gave the lowest one in the performance. This can be easily related to the extreme solvent entrapment inside the film that in turn actively hinders the charge transport in the devices. Thus the performance is lower. Since the nature of annealing and the solvent evaporation strongly influence the structure of the films, further study on the optimization of annealing treatment as well as the selection of suitable solvent that facilitates the formation of compact structure during the solvent evaporation is in progress.

\section{Acknowledgments}

The authors would like to thank the Malaysian Ministry for Higher Education and University Kebangsaan Malaysia for the research grants (UKM-RRR1-06-FRGS0002-2007, UKM-GUP-NBT-08-25-086 and UKM-OUP-NBT-27-120/2010).

\section{References}

[1] C.N. Hoth, S.A. Choulis, P. Schilinsky, C.J. Brabec, J. Mater. Chem. 19, 5398 (2009).

[2] V. Fauzia, A.A. Umar, M.M. Salleh, M. Yahaya, Mater. Sci. Forum 663-665, 823 (2011).

[3] C.N. Hoth, S.A. Choulis, P. Schilinsky, C.J. Brabec, Adv. Mater. 19, 3973 (2007).

[4] T. Aernouts, T. Aleksandrov, C. Girotto, J. Genoe, J. Poortmans, Appl. Phys. Lett. 92, 033306 (2008).

[5] C.N. Hoth, P. Schilinsky, S.A. Choulis, C.J. Brabec, Nano Lett. 8, 2806 (2008).

[6] C.N. Hoth, P. Schilinsky, S.A. Choulis, C.J. Brabec, Macromol. Symp. 291-292, 287 (2010).

[7] S.H. Eom, H. Park, S.H. Mujawar, S.C. Yoon, S.S. Kim, S.I. Na, S.J. Kang, D. Khim, D.Y. Kim, S.H. Lee, Organic Electron. 11, 1516 (2010).

[8] A. Lange, M. Wegener, C. Boeffel, B. Fischer, A. Wedel, D. Neher, Solar Energy Mater. Solar Cells 94, 1816 (2010).

[9] V. Fauzia, A.A. Umar, M.M. Salleh, M. Yahaya, Adv. Nat. Sci., Nanosci. Nanotechnol. 2, 01501 (2011).

[10] S.H. Eom, S. Senthilarasu, P. Uthirakumar, S.C. Yoon, J. Lim, C. Lee, H.S. Lim, J. Lee, S.H. Lee, Organic Electron. 10, 536 (2009). 
[11] D. Jones, in: Organic Photovoltaic, Eds. C. Brabec, V. Dyakonov, U. Scherf, Wiley-VCH, Weinheim 2008, p. 310 . 